\title{
PIEZAS CERÁMICAS EMBLEMÁTICAS DEL SEÑORÍO DE LOS CORELLA EN EL VALLE DE ELDA (siglo XV)
}

\author{
A. M. POVEDA NAVARRO
}

\section{Cerámicas heráldicas de los Corella en el castillo de Elda.}

Algunos de los trabajos de desescombro, limpieza y excavación arqueológica realizados en la primera mitad de la década de los años ochenta, en el interior del castillo de Elda, han aportado piezas arqueológicas de evidente interés histórico y artístico.

En el corte VI-E, del sector noroeste del castillo, se pudo aislar un nivel con cerámicas comunes y loza de lujo, fragmentos de objetos de vidrio, una moneda (dinero de vellón) de Alfonso $V$ y restos de elementos constructivos entre los que destacamos los justificativos de este artículo, es decir unos azulejos valencianos de significado heráldico.

Todo el conjunto de materiales se fecha en el siglo XV, debido a la presencia de cerámicas de Manises y de Paterna junto a esa moneda.

Los azulejos que nos interesan están practicamente inéditos, únicamente se han dado a conocer dos de ellos(1) y además sin el estudio detallado que merecen.

El lote hallado está muy fragmentado por lo que solamente presentamos las piezas mejor conservadas, excluyendo los fragmentos de azulejos cuadrados (rajoles) decorados con roseta estilizada central, de azulejos hexagonales (alfardones) con peinetas o con leyenda en valenciano, que se han documentado en la cuadrícula VI-E, constituyendo un conjunto de lose- 
tas cerámicas idénticas a las aparecidas en escombreras de Manises, para las que se propuso una composición pavimental como la que ilustra la figura 1.(2)

Se trata de unos azulejos cubiertos con una capa de barniz estanífero bajo la que se han pintado en azul cobalto varios motivos decorativos heráldicos que se transparentan en el barniz, que les protege del desgaste, ya que son piezas para chapar suelos medievales. Si bien se las suele combinar con losetas bizcochadas, cuando corresponden a conjuntos de gran magnificencia se prescinde de éstas(3), como parece ocurrió con las del castillo de Elda.

En tales casos los pavimentos combinaban azulejos alfardones con rajoles. A veces a los emblemas representados sobre los azulejos les acompaña una leyenda que se constituye en elemento principal de la pieza, como ocurre en nuestro lote.

\section{Catálogo de azulejos.}

1. Rajola cuadrada, decorada con motivos heráldicos del noble valenciano Ximén Pérez de Corella, pintados en azul cobalto bajo barniz estanífero. Un recuadro de doble y fino filete conservado en los flancos derecho e inferior encierra a aquellos: cuerpo de serpiente con cabeza de mujer a cuyo cuello se enrosca la cola describiendo un círculo. Entre éste y los ángulos del recuadro aparecen hojas estilizadas típicas de la época, conservándose únicamente la del ángulo superior derecho y la del ángulo inferior izquierdo de forma parcial. El reptil contiene un escudo cuarteado con los siguientes elementos: en el cantón diestro del jefe dos barras o palos verticales, en el centro del jefe cuatribarrada en horizontal, en el cantón siniestro del jefe dos flores de Lis una sobre la otra y una cruz tipo Santo Sepulcro o Tierra Santa, que presenta en el interior de sus ángulos rectos pequeñas cruces de San Andrés o decussata, y no las normales cruces griegas, ocupan el flanco diestro otra cuatribarrada horizontal, las flores de Lis - esta vez sobre fondo azul - y la misma cruz de Tierra Santa, el centro del cuerpo y el flanco siniestro contienen dos dobles barras verticales y dos águilas sin corona, el cantón diestro de la punta y parte del centro de ésta son de campo azur, y el resto del centro y el cantón siniestro de la punta acogen una campana, parcialmente visible debido a la rotura del azulejo.

La cerámica es de color rojizo ladrillo en su núcleo y amarillenta en la superficie.

Observación: contiene restos de argamasa del tipo yeso en su superficie posterior o base, para fijarla al suelo. 
Dimensiones: $11,3 \times 11 \mathrm{cms}$. de lado en lo conservado y $2,1 \mathrm{cms}$. de grosor.

Taller productor: alfares de Manises.

Cronologia: años $1.444-1.446$

2. Alfardón hexagonal, decorado con leyenda heráldica: SDEVENIDOR del noble valenciano Ximén Pérez de Corella, que está pintada en azul cobalto bajo barniz estanífero. Una orla de huesecitos en serie en el interior de una banda delimitada por dos dobles filetes recorre todo el perímetro del hexágono.

La leyenda está escrita en valenciano con letras góticas que presentan varios nexos: SDEVENIDOR (DE, VEY DO).

La cerámica es de color rojizo ladrillo en su núcleo y amarillenta en la superficie.

Observación: contiene restos de argamasa del tipo yeso en su superficie posterior o base, para fijarla al suelo.

Dimensiones: $21,5 \times 11,8 \mathrm{cms}$. tiene de largo por ancho y $2,5 \mathrm{cms}$. de grosor.

Taller productor: alfares de Manises

Cronología: años $1.444-1.446$.

3. Mitad derecha de un alfardón como el anterior. Todas las características son idénticas con la pieza número 2 .

La leyenda conservada es [SDEVE]NIDOR (nexo DO), con ligeras variantes paleográficas: la letra "o" en nexo la "d" no aparece del todo cerrada por la parte superior; el apéndice final de la letra "r" es extremadamente largo. Ello es lógico pues la leyenda se realizaba pintada a mano.

Dimensiones en lo conservado: $11 \times 11,7 \mathrm{cms}$. de largo por ancho y 2,3 cms. de grosor.

4. Dos fragmentos de un posible mismo alfardón, que en esta ocasión tiene por decoración una peineta y una orla de huesecitos idéntica a las de los azulejos números 2 y 3 . Todas las características morfológicas son idénticas a las de éstos.

Dimensiones conservadas en el fragmento mayor: $9,2 \times 10 \mathrm{cms}$. de largo por ancho y $2,1 \mathrm{cms}$. de grosor.

Dimensiones conservadas en el fragmento pequeño: $6,5 \times 7,5 \mathrm{cms}$. de largo por ancho y 2,2 cms. de grosor.

-Interpretación: La decoración de tipo heráldico como tema central de 
los azulejos de Manises jugó un papel muy importante, en nuestra rajola esta circunstancia se vuelve a verificar.

Nos dice Martín de Viciana(4) que Ximén Pérez de Corella usaba por timbre "una culebra que da vueltas por todo el escudo; en la cabeza del escudo, la culebra tiene cabeza y rostro como de mujer, con llamas de fuego, y con la cola ciñe su cuello", y el lema Esdevenidor. Añade G. Escolano que en una tabla pintada de las tres colocadas en el año 1.445, en la portada de San Juan de Letrán, Roma, por el papa Eugenio IV, y sus nobles, entre ellos don Ximén, se veía la divisa de éste: "culebra con cabeza de mujer, y muchas roscas en la cola"(5). Además, en la calle Santos Metges, de Cocentaina (Alicante), población medieval donde obtuvo el título de conde a partir del año 1.448, existe un relieve en el que dos ángeles sostienen el escudo de armas de los Corella, que aparece rodeado por el reptil con cabeza femenina a cuyo cuello se enrosca la cola(6). Por último, un escudo de los Roiç de Corella, de campo de gules con rectángulo plateado en cuyo centro hay una cruz de Tau plateada, presenta en lo alto una cabeza de mujer a la que se enrosca una serpiente, en la base el letrero Esdevenidor(7).

Con todos estos datos debemos admitir, sin reparos, que en nuestro azulejo se representa la tan citada divisa de Ximén Pérez de Corella y sus descendientes.

Respecto al escudo de armas que aparece en el interior del círculo descrito por el reptil, su identificación está bastante facilitada con el análisis anterior y las mismas fuentes.

Al parecer de Viciana el escudo de armas primitivo de la familia Corella era "de gules, una cruz-paté de plata"(8) y la divisa de la serpiente con cabeza de mujer. Esta sería la heráldica antigua quizás con la variante posible de que la cruz no fuese pateada y si de tau, como la tenemos constatada.

Sin embargo, desde el año 1.442, cuando Ximén toma Nápoles para el rey de Aragón Alfonso $V$, éste le concede $\epsilon$ l uso de sus propias armas reales, es decir, las de Aragón y las Dos Sicilias(9): dos o cuatro barras por la corona de Aragón y cuatro barras y las dos águilas de la Casa de Suabia por las Sicilias. Además, por ser el conquistador de Nápoles también pudo incorporar a sus armas la heráldica napolitana: sembrado de lises de la Casa de Anjou, y la cruz de Tierra Santa, del pretendido reino de Jerusalén. A todos esos elementos hay que unirles las armas propias de Ximén: barras como las de Aragón y una campana y el mote Sdevenidor(10).

De modo que ya podemos identificar totalmente el escudo de armas de la rajola del Castillo de Elda: Barras por Aragón y el Corella, tres cuarteles por Nápoles, el primero cuatribarrado, el segundo con dos flores de 
lís y el tercero con la cruz de Tierra Santa, después se repiten estos tres cuarteles napolitano-aragoneses, a los que siguen cuatro barras y dos aguilas representantes de las Dos Sicilias, por último una campana heráldica del Corella. Además, este es el tipo del escudo del relieve de Cocentaina ya aludido.

Al faltar el mote o lema Esdevenidor o Sdevenidor en el escudo de armas de esta rajola, se necesitó combinarla con alfardones que portasen dicha leyenda, que es la que aparece en las piezas números 2 y 3 , que estarían acompañadas por otras como la número 4 y las que no hemos presentado aquí, del tipo roseta, pero que aparecen con todas ellas en la fortaleza medieval de Elda y en las escombreras de Manises, demostrando que formarian un mismo pavimento en aquellas construcciones pertenecientes a Ximén Pérez de Corella.

El hecho de que éste disponga de azulejos con las armas reales de Alfono $\mathrm{V}$, de Aragón y las Dos Sicilias y Aragón y Nápoles, nos ilustra fehacientemente la importancia que alcanzó Ximén ante el rey y la sociedad valenciana de la época, algo que como veremos en este estudio lo testimonian igualmente las fuentes escritas, que en este caso se refrendan con las arqueológicas.

Sabemos que en el año 1.442 su rey le puso al frente de la conquista de Nápoles, lo cual consiguió con gran brillantez, por ello el monarca le concede libre y espontáneamente el uso de sus propias armas, que hasta ese momento eran las de Aragón y de las dos Sicilias(11).

Sin embargo en la rajola de Elda aparecen junto a las armas de Ximén, las de Aragón y las Dos Sicilias, pero también las del Nápoles aragonés, por tanto estamos ante un escudo de armas posterior a la conquista de Nápoles (1.442).

Entre el año 1.444, cuando se conoce al famoso azulejero de Manises, Johan Almurcí, y el año 1.446, cuando el rey Alfonso $V$ le paga 3.766 sueldos por las 13.458 "rajolets" con las armas de Aragón y Sicilia y de Aragón y Nápoles, se debieron fabricar los azulejos heráldicos de Ximén, pues sólo entonces pudo encargarlos tomando los elementos a partir de los representados en las armas reales sobre los azulejos encargados por el monarca, destinados a las solerías del "Castel Novo" de Nápoles y tal vez del de Gaeta(12).

Muy probablemente, las rajolas y los alfardones de la estancias principales de Ximén en su Castillo de Elda, fueran fabricadas en Manises por el citado Johan Almurcí, en la misma época que se hicieron los azulejos de Alfonso $\mathrm{V}$, el gran protector de Ximén, por tanto entre los años $1.444 \mathrm{y}$ 1.446 . 


\section{Los Corella en el siglo XV}

La importancia del noble Ximén Pérez de Corella comenzó a acrecentarse desde 1420, siguiendo al rey Alfonso III de Valencia y $V$ de Aragón, el Magnánimo, en sus expediciones a las islas de Córcega y Cerdeña y en el asalto de Bonifacio; en 1423 cayó prisionero en Nápoles al ser tomada por Sforcia, al ser liberado y regresar con Alfonso $V$ participó en el asalto de Marsella, siendo uno de los caballeros que rompieron las cadenas de su puerto para que entrasen en él las naves aragonesas(13).

El 25 de octubre de 1424, la reina Violante vendía a Ximén el valle y castillos de Elda y Aspe, con sus términos y derechos anexos(14).

Según la Crónica de Almunia (fols. 124-125), Ximén Pérez ya venía siendo gobernador general del Reino de Valencia entre 1416 y 1429, año en el que fue sucedido en el cargo por su hijo Juan Ruiz de Corella(15), después volvió a ocuparlo y se le sustituiría cada vez que se ausentase. El 28 de mayo de 1429, en Barcelona, el rey Alfonso le nombró virrey de la ciudad y Reino de Valencia(16), como recompensa a sus grandes servicios prestados a la Corona. Zurita(17) nos dice que fue virrey de Valencia en 1430,1432 y 1434, siendo lugarteniente general del Reino de Valencia durante toda su vida. En 1432 es nombrado por el rey capitán de su armada expedicionaria a Africa. En 1434 reaparece en Nápoles como consejero del rey Alfonso V. En el asalto y toma de Nápoles, en 1442, Ximén Pérez de Corella fue uno de los caballeros más distinguidos(18), por lo que obtuvo del rey, para él y para sus descendientes, el uso de las armas reales haciéndole además la gracia de tres mil ducados anuales de renta vitalicia "sobre las gabelas de las entradas y salidas de aquella ciudad de Nápoles»(19).

Por privilegio firmado el 24 de octubre de 1446, el rey Alfonso dispuso que a Ximén Pérez de Corella, virrey vitalicio de la ciudad y Reino de Valencia, le sucediera su hijo, Juan Ruiz de Corella, cuando aquél lo dejase vacante por cesión, renuncia o muerte, y gozaría con las mismas facultades, gracias y prerrogativas que su padre(20). El 10 de agosto de 1448 renuncia Ximén en su hijo, que recibe el cargo, también, de forma vitalicia, estableciéndose que si Juan Ruiz lo dejase vacante le sucedería únicamente su padre.

Entre las familias prepotentes eran frecuentes los conflictos, así ocurría entre los Corella y los Cornell, entre Juan Ruiz hijo de Ximén, y Luis Cornell, éste era gobernador de la Gobernación o Procuración de Orihuela; Juan Ruiz era el virrey o lugarteniente general del Reino de Valencia y de la ciudad valentina. El 10 de agosto de 1448 el rey daba un privilegio(21) por el que los Corella se zafaban de la jurisdicción abusiva y vengativa, que los Cornell ejercian sobre las principales propiedades de los Corella en la Gobernación de Orihuela (Elda, Aspe, Petrel y Salinas). 
El 28 de agosto de 1448, Alfonso $V$ vende la villa y Baronía de Cocentaina a Ximén Pérez de Corella, por la suma de 80.000 florines de oro, y en agradecimiento a sus grandes servicios le concede el título de Primer Conde de Cocentaina(22). El 10 de abril de 1450, por privilegio real y tras renuncia de su hijo, Juan Ruiz, volvía Ximén a ser virrey de Valencia. Ximén actuó a veces como embajador del rey Alfonso $\mathrm{V}$, y como miembro destacado de su Consell. Como tal le fueron confiadas importantes misiones diplomáticas: ante el papa Eugenio IV (1445) y el papa Nicolás V, con Juan Olzina (1447), ante su hermano Juan de Navarra para obtener subvenciones de las cortes de sus reinos, con Juan de Moncayo (1451), ante el rey de Castilla, con Ferrer de Lanuza; Galcerán de Requesens (1452 y 1453) para mediar en pro de la paz, y ante el papa Calixto III para obtener su confirmación de la investidura del reino de Sicilia entre otros asuntos $(1456)^{(23)}$.

Ximén Pérez de Corella se convirtió en uno de los más brillantes soldados del siglo $\mathrm{XV}$, además de uno de los mejores diplomáticos del rey Alfonso $V$, circunstancias que le sirvieron para ser uno de los nobles más protegidos por dicho monarca(24).

El 17 de octubre de 1457 moría Ximén Pérez de Corella, I Conde de Cocentaina, siendo enterrado en la Iglesia Catedral de Nápoles. Fue una gran pérdida político-militar para la Corona Aragonesa. Ximén empezó como copero del rey Alfonso $\mathrm{V}$ y llegó a ser el gobernador general de Valencia, alcanzando tal confianza que se le encargó la educación del infante Fernando, bastardo del rey, nacido en Valencia y llevado por Ximén a Nápoles junto a su padre. El historiador medieval Pandulfo Colemicio, confiesa en su Historia de Nápoles que «todo el gobierno del rey pendía de él y de Ramón Boyl».

Le sucedió su hijo Juan Ruiz de Corella, tanto en el Condado de Cocentaina como en el virreinato de Valencia y en los Señoríos de su padre, entre ellos el del valle de Elda, según privilegio de 19 de octubre de 1457(25). Al igual que su padre «consagró por entero toda su vida al servicio de los reyes de Aragón, al gobierno y prosperidad del Reino de Valencia y al cuidado y recta administración de su Condado de Cocentaina»(26). Este II Conde sufrió las hostilidades de otras dos nobles familias, la de los Urrea y la de los Maza de Lizana. Se repitió la misma historia de la época de los Cornell, y acabó igual, con una provisión expedida por Juan II, en Villafranca de Penades, el 25 de octubre de 1469.(27)

Juan Ruiz y su hijo Ximén Pérez, guerrearon contra el Marqués de Villena, así el 20 de marzo de 1476 sitiaron y cercaron Sax, rindiendo su fortaleza el 4 de junio de ese mismo año. Por su exito en el sitio de Ludiente y su victoriosa campaña contra el rebelde Jaime de Aragón, recibió Juan Ruiz gracias y privilegios de Juan II el 3 de mayo de $1477^{(28)}$. El II Conde de 
Cocentaina Juan Ruiz de Corella y Llanzol de Romaní murió en 1478, sucediendole en el Condado su primogénito, Juan Ruiz de Corella y de Moncada, III Conde, que a imitación de su padre y de su abuelo prestó grandes servicios al rey Juan II y a su hijo el rey Católico, Fernando, éste le confirmó o prorrogó los privilegios que tenian sus antecesores por quince años más, mediante privilegio expedido en Alcalá de Henares, el 25 de diciembre de 1497(29). El 16 de julio de 1519 moría el III Conde, Juan Ruiz de Corella y de Moncada, sin sucesión legítima, heredó la villa y Condado de Concentaina, con todos los demás bienes vinculados pertenecientes la Casa de Corella, su hermano Rodrigo Ruiz de Corella y de Moncada, el 18 de julio de ese año (desde 1513 el Señorío del valle de Elda ya no pertenecía a los Corella, sino a los Coloma que lo adquirieron de éstos).

\section{Orígen y Formación del señorío de los Corella en el Valle de Elda}

Compra del valle de Elda y sus derechos por Ximén Pérez de Corella

El 25 de octubre de 1424, la reina Violante de Bar vendió a Ximén Pérez de Corella el valle y castillos de Elda y de Aspe, con sus respectivos términos y derechos a ellos anexos, por la cantidad de 43.650 libras, moneda de Barcelona. El protonotario de Violante, Jaime Valls, notario público en todos los dominios del rey de Aragón, autorizó la venta. El 19 de septiembre de 1425, Ximén Pérez de Corella obtenía documento de venta de un censo de 5.000 sueldos anuales que pesaba sobre los derechos de Elda y Aspe, comprando este censo a Alfonso V por 15.000 florines de la ley de Aragón, equivalente a 95.000 sueldos reales del Reino de Valencia. El 25 de octubre de ese mismo año el monarca aragonés Alfonso $\mathrm{V}$, mediante privilegio real aprobaba la venta realizada un año antes por la reina Violante, de modo «que el nuevo señor de Elda entró en inmediata posesión de nuestra población y castillo»(30).

La realidad histórica vivida por el valle de Elda, bajo el señorío de los Corella, la podemos esquematizar en los siguientes puntos (a desarrollar en un trabajo más amplio).

\section{Conflictos de límites territoriales}

El primero data de 1428, entre Novelda y Elda, entre Pedro Maza de Lizana y Ximén Pérez de Corella, sus respectivos señores. El arbitraje del rey Alfonso puso fin al conflicto, se fijaron los lindes y se estableció la pena de 5.000 florines de oro para quien no los respetase, según decreto real expedido en Murviedro el 6 de diciembre de 1428(31). El segundo conflicto fue en 1503, entre Castalla y Petrel, entre Aldonza Ladró de Rocafull, señora de 
la villa y Baronía de Castalla y Juan Ruiz de Corella, III Conde de Cocentaina y Señor de Elda, Petrel y Salinas. Con autoridades y testigos de ambas partes se fijaron los lindes, y se estableció que las reformas o restauraciones de ellos se harían previa convocatoria de una de las partes y siempre en presencia de una de ellas. Asi quedó escrito el 4 de julio de 1503(32).

\section{Enfrentamientos nobiliarios}

Las tensiones surgidas entre los Maza de Lizana y los Pérez de Corella, en los años 1427 y 1428, obligaron a intervenir a Alfonso $V$ que logró instaurar una tregua entre ambas partes(33).

La enemistad entre los Cornell y los Corella, entre Luis Cornell, gobernador de la Gobernación de Orihuela, y Juan Ruiz de Corella, virrey o lugarteniente general de la ciudad y Reino de Valencia, repercutía en represalias sobre los vasallos habitantes de las propiedades de los Corella en dicha Gobernación: Elda, Aspe, Petrel y Salinas. Por eso Ximén Pérez y su hijo Juan Ruiz acudieron al rey Alfonso demandando quedar exentos, ellos y sus vasallos en esas tierras, de la discriminatoria y nefasta jurisdicción de Cornell. El rey accedió a la demanda por privilegio de 10 de agosto de $1448^{(34)}$, de modo que los Corella y sus vasallos, los de Elda y su valle, se zafaban de los abusos y venganzas de los Cornell. La misma situación se reprodujo entre los Maza de Lizana y los Corella, entre Pedro Maza de Lizana y Juan Ruiz de Corella, ya sus padres se habían enfrentado en el conflicto territorial de Novelda y Elda, ya expuesto.

A comienzos del año 1469 surgió un nuevo enfrentamiento entre ambas familias y sus posesiones en dichas poblaciones, en este caso las tensiones se debían a la construcción de un molino en Elda cerca del linde con Novelda(35). Sin embargo esto fué una simple escaramuza con respecto a la situación creada a continuación.

Pedro Maza desde su privilegiado puesto de gobernador de la Gobernación oriolana actuaba contra los señoríos de los Corella en ésta. Ahora las hostilidades fueron graves: cada vez que se presentaban en Elda los recaudadores de tributos de la Gobernación, eran maltratados, según reflejan las diligencias instruidas por los escribanos reales; Pedro Maza sólo podía visitar Elda y Aspe de noche, con secreto y acompañado de caballos y soldados a pie(36). La Gobernación armó una tropa y se dispuso a atacar Elda, que a su vez se preparó para la batalla. Esta se evitó por la prudencia impuesta por el Adelantado de Murcia, y porque notificado el rey Juan II de todo lo ocurrido y de lo que podía ocurrir, ordenó que no se iniciase acción alguna. Como antes hiciera Alfonso V, ahora Juan II aceptaba la demanda de los Corella de quedar exentos de la jurisdicción directa de los Maza de 
Lizana en sus señoríos citados de la Gobernación. Así se fallaba en la provisión expedida en Villafranca de Penadés, el 25 de octubre de 1469(37).

\section{Belicismos entre las Coronas de Aragón y de Castilla}

La intromisión de Alfonso $\mathrm{V}$ de Aragón en los asuntos de estado castellanos implicó la guerra con Castilla (23 de junio de 1429). El valle de Elda participó en la contienda, por obligación o por su voluntad, al menos en 1430, y lo hizo auxiliando a las tropas castellanas de Juan If de Castilla. Alfonso V debió entender que ello se hizo forzadamente ya que dicho valle pertenecía al señorío de Ximén Pérez de Corella, su virrey de Valencia y principal militar de dicho monarca, al cual le debió de dar una buena explicación en defensa de sus vasallos. Así se entendería que Alfonso $V$ expidiese, el 16 de octubre de 1430, un salvoconducto a favor de las villas de Elda, Aspe y lugar de Petrel $<<$ sitos en la frontera castellana a cuyo rey castellano habían prestado auxilio >, y evitar de esta forma que las tropas aragonesas castigaran a sus habitantes(38).

En otra ocasión, Juan Ruiz de Corella y su hijo Ximén Pérez de Corella por parte de Aragón, y el poderoso Maestre de Santiago, el Marqués de Villena, por parte de Castilla, se hallaban guerreando intensamente y en uno de los lances del conflicto los Corella sitiaron y cercaron Sax con «noventa y dos de a caballo", el 20 de marzo de 1476, según narra Diago en sus Apuntaciones, y rindieron la fortaleza el 4 de junio de ese año. Muy probablemente el valle de Elda, señorío de los Corella, serviría de "quintacolumna a éstos, sobre todo desde el bastión amurallado de La Torreta, especial vigía de la zona de Sax. De modo que de alguna forma los vasallos intervendrían en apoyo de su señor el Conde de Cocentaina(39).

\section{La opresión sobre la mayoría musulmana}

La inestabilidad social en la Gobernación de Orihuela era grande y en el valle de Elda, con una población mayoritariamente musulmana bajo un poder cristiano minoritario, la tensión social era alta. La llegada de los Corella traería consigo la venida de familias aragonesas o valencianas a partir de 1424 , originándose una competitividad a todos los niveles entre la comunidad musulmana y la comunidad cristiana, aragonesa, ello podría justificar uno de esos típicos ataques a la morería ,que se produjo en Elda en 1428(40).

La población musulmana no gozaba de libertades, para salir del valle debían portar un salvoconducto. Sabemos que en 1477 muchos moros del valle de Elda habían incurrido en gravísimas penas, por trasladarse sin orden ni licencia del rey a otras tierras de moros y también al Reino de Castilla, y 
al parecer con intenciones no muy claras. El resultado fue el encarcelamiento de los musulmanes y el confiscamiento de sus bienes, situación que se agravó con el intento musulmán de evadirse de los oficiales del Conde(41).

Por otro lado, el miembro de cualquier minoría confesional es objeto de trato discriminatorio, es siempre víctima propiciatoria de delincuentes y desaprensivos. El musulmán debía desplazarse acompañado de cristianos amigos, y aun así no estaría del todo seguro. Abd Allah Manona, moro de Elda, regresaba de Alcoy a Elda acompañado de un cristiano, al pasar por la pinada de lbi, el acompañante, que resultó ser un almogávar de Orihuela, le descargó cuatro golpes que le hicieron huír precipitadamente abandonando a su mula y todas sus pertenencias: paños y otras mercancías, 8 libras y 16 sueldos. Abd Allah fue a lbi a denunciar el hecho ante el bayle, que no le ayudó y encima le incautó los 52 sueldos que le quedaban. El mudéjar es siempre el culpable(42).

\section{Franquicias, Diezmos y Primicias. Contraprestaciones}

Ximén Pérez de Corella, como Señor del lugar de Petrel, perteneciente al valle de Elda, consiguió, el 28 de abril de 1438, que gozara de franquicia e inmunidad al igual que se supone que las disfrutarían Elda y Aspe desde casi los primeros años de su paso a manos de Ximén. El privilegio lo confirmó el rey en Capna (Italia), el 19 de marzo de 1441(43).

Ya hemos visto en otro punto anterior las franquicias dadas a los Corella por los reyes Alfonso $V$ y Juan II (1448 y 1469) para zafarse de la jurisdicción abusiva de los gobernadores de la Gobernación de Orihuela, en materia de causas civiles y criminales. La familia Corella con sus criados y dependientes, como a los alcaides de sus castillos, los procuradores y receptores, los agentes de sus negocios, los mensajeros y embajadores, así como a todos sus vasallos, ya sean cristianos, judíos o moros, con todas las villas, lugares y alquerías de su propiedad, todos ellos eran los beneficiados de los privilegios que daban esa concesión y que hemos visto ya en el punto que trataba de los roces nobiliarios.

Normalmente, los Papas agraciaban a los monarcas que abrazaban y defendían la causa católica, con la concesión de los diezmos y primicias que los fieles pagaban a la Iglesia. Y los reyes solían transferir esa gracia a sus mejores vasallos en recompensa de servicios prestados. Así actuó Alfonso $V$ con Ximén Pérez de Corella, a quien concedió los diezmos y primicias de las villas, lugares y castillos de Elda, Aspe, Petrel y Salinas, que eran Señorío de Ximén, «con todos y cada uno de los derechos, propiedad, acciones, usos y utilidades que al rey competían por razón de esta gracia pontificia»(44); le otorgó este privilegio de forma vitalicia, con facultad para dar, enajenar o 
arrendar este derecho por su libre voluntad. El privilegio se expidió en Castelnuovo (Nápoles), el 5 de febrero de 1449.

Otros privilegios o franquicias son del tipo del privilegio dado por Juan Il a Juan Ruiz de Corella, en Tortosa, el 3 de mayo de 1477, por su éxito en el sitio de Ludiente y su campaña victoriosa frente al rebelde Jaime de Aragón. La recompensa real fue la concesión al Conde de los bienes confiscados a los moros del valle de Elda, que en el punto referente a la opresión de los musulmanes habíamos visto encarcelar, por salir del valle sin licencia o permiso y que luego trataron de huir de los oficiales del Conde(45).

Importantísimo fue el privilegio concedido por Fernando el Católico, en materia de impuestos, a Juan Ruiz de Corella y Moncada, III Conde de Cocentaina, que expedido en Alcalá de Henares, el 25 de diciembre de $1497^{(46)}$, le prorrogaba en quince años más el privilegio de sus antecesores y le daba plena facultad y licencia para establecer y ordenar sisas o imposiciones en la forma que mejor le pareciese, sobre el pan, vino, aceite, carne, pescado otros artículos comestibles, extendiendo esta facultad y licencia a todos sus herederos y sucesores en la villa de Cocentaina, en Elda, Aspe y Petrel, añadiéndole la facultad para poder cambiar aumentar, disminuir, quitar o modificar como mejor le pareciese dichas imposiciones; así como para venderlas, arrendarlas o enajenarlas, cediéndole además la quinta parte del dinero recaudado por medio de estas imposiciones, que por costumbre se reservaba a la Curia Real.

En el apartado de las contraprestaciones de los Corella, al margen de las preceptivas como Señores feudales que eran, es esencialmente reseñable, en lo referido al culto religioso, la contrapartida a la concesión de diezmos y primicias eclesiásticos hecha por Alfonso V a Ximén Pérez de Corella, el 5 de febrero de 1449, el Papa Nicolás $V$ le confirmó a Ximén tal concesión por sus servicios prestados a la Santa Sede, pero con la condición de edificar tres iglesias en Elda, Aspe y Petrel, y mantener a dos sacerdotes con la dotación de 500 libras anuales y perpetuas $(47)$; con ello obtendría también el Patronato, para sí y para sus herederos y sucesores, sobre las nuevas iglesias por él fundadas. Todo según bula de 24 de mayo de 1449, dada en Roma. La cual era ratificada, con modificaciones, por la bula de 12 de mayo de 1451 de Nicolás $V$. Ahora se especificaba cuántas iglesias y dónde se han de edificar por parte del beneficiado: «una iglesia en Elda y otra en Aspe», y con la obligación de «dotarlas, y además la de pagar anualmente 70 libras, o sean 1.050 reales de vellón al obispo de Cartagena a cuya diócesis pertenecían ambos pueblos»(48). Esta bula debía ser un recordatorio y una confirmación de la primera bula para el Conde, y aún asi ni éste ni los que le sucedieron en la obligación cumplieron con ésta, tendrían que llegar los Coloma, en el siglo XVI, para fundar, el 6 de diciembre de 1528, la exigida parroquia de Elda. En 1494 se insistía aún en esa obligación, asi mediante una concor- 
dia celebrada en Aspe, el 30 de agosto de ese año, entre el Obispo y Cabildo de Cartagena y Juan Ruiz de Corella, III Conde de Cocentaina, este último se comprometía a mantener a los presbíteros que se ocupaban del culto en las ermitas, iglesias y parroquias del territorio bajo su jurisdicción, también se obliga el Conde y sus sucesores a pagar a dicho Obispo y Cabildo cartagenero 200 libras valencianas(49).

\section{Economía del valle de Elda}

\section{a) Comercio}

Lo tenemos documentado esencialmente en la concesión de una Feria para Elda, después de que Juan Ruiz de Corella la hubiera demandado a Juan II , y éste «concedió el privilegio para que se celebrara la Feria de Elda el día 1 de octubre de cada año". El documento lo estudió L. Amat en un original del A.M.E. que se complementa con otro analizado por M. Ruzafa junto con el de la concesión anterior de un mercado semanal en la villa de Elda, que había sido solicitado por Ximén Pérez de Corella y obtenido de Alfonso $V$ en 1426 (5 de septiembre)(50). Ambos nos dicen que la concesión se hizo "según Rescripto dado en la villa de San Mateo el día 22 de marzo de 1466 . En la Feria se vendían «ropas y pañolería de paño, terciopelo, seda, lana, hilo, algodón para vestir, ferreteria, herramientas, cordelería y otros útiles de labranza y oficios", también correas para aparejos de caballerías y carros; no se hacían transacciones y negocios a gran escala pero al concurrir todos los pueblos circunvecinos a proveerse, la venta al pormenor era bastante importante. Dicha Feria se trasladó a los días del 1 al 13 de diciembre de cada año por decreto de la reina de Castilla, Juana, viuda de Felipe el Hermoso, expedido en Zaragoza, el 30 de Julio de 1518, en favor de Juan de Coloma, por sus buenos servicios como secretario de los Reyes Católicos.

\section{b) Agricultura}

La economía del valle era básicamente agropecuaria, y en ella era primordial la agricultura, normalmente secano, la escasez de agua era ya agobiante. Para proteger a la agricultura se tuvo que traer agua desde el valle alto del río Vinalopó, de Villena y de Sax. Gracias a J. M ${ }^{a}$. Soler García(51) conocemos una carta expedida, el 31 de julio de 1493, por Juan Ruiz de Corella al Concejo de Villena, en ella se agradece el ofrecimiento de agua de la Fuente del Chopo y del Carrizo Blanco, tan necesaria para Elda, mayoritariamente poblada por musulmanes, los moriscos, que sustentaban secularmente la agricultura, necesidad aclarada con la explicación: "ya que los moros están en ayuno y antes de su Pascua no se les puede negar el agua 
de dicha fuente-. Pero la huerta del valle de Elda seguiría necesitando más agua para su riego. Tal situación forzó al Conde Juan Ruiz de Corella a adquirirle a Sax su Fuente de la Torre del Emperador, que se realizó mediante concordia de 29 de octubre de 1512, de esta forma el Conde compraba agua para sus vasallos de Elda. El documento de la concordia estuvo en el A.M.E., de donde lo extractó Lamberto Amat y de quien a su vez fue recogido por A. Navarro Pastor(52).

\section{Venta del valle de Elda a los Coloma}

A finales del siglo XV la familia Corella presentaba una situación económica en franca decadencia, de ahí que tuvieran que desprenderse de muchas de sus propiedades. A finales de 1497 vendió la Baronía de Aspe a Gutierre de Cárdenas, señor de Elche. Poco después, el 28 de noviembre de 1498, se configuró el precontrato de enajenación de Elda en favor de Juan Pérez Calvillo de Coloma (nieto de Juan Coloma, secretario de los Reyes Católicos), con la autorización del notario Juan López de la Fanaga. La venta sería efectiva el 4 de septiembre de 1513, en Valencia y ante Miguel Frígola(53), consumándose así el paso de Elda y su valle de manos de los Corella a manos de los Coloma.

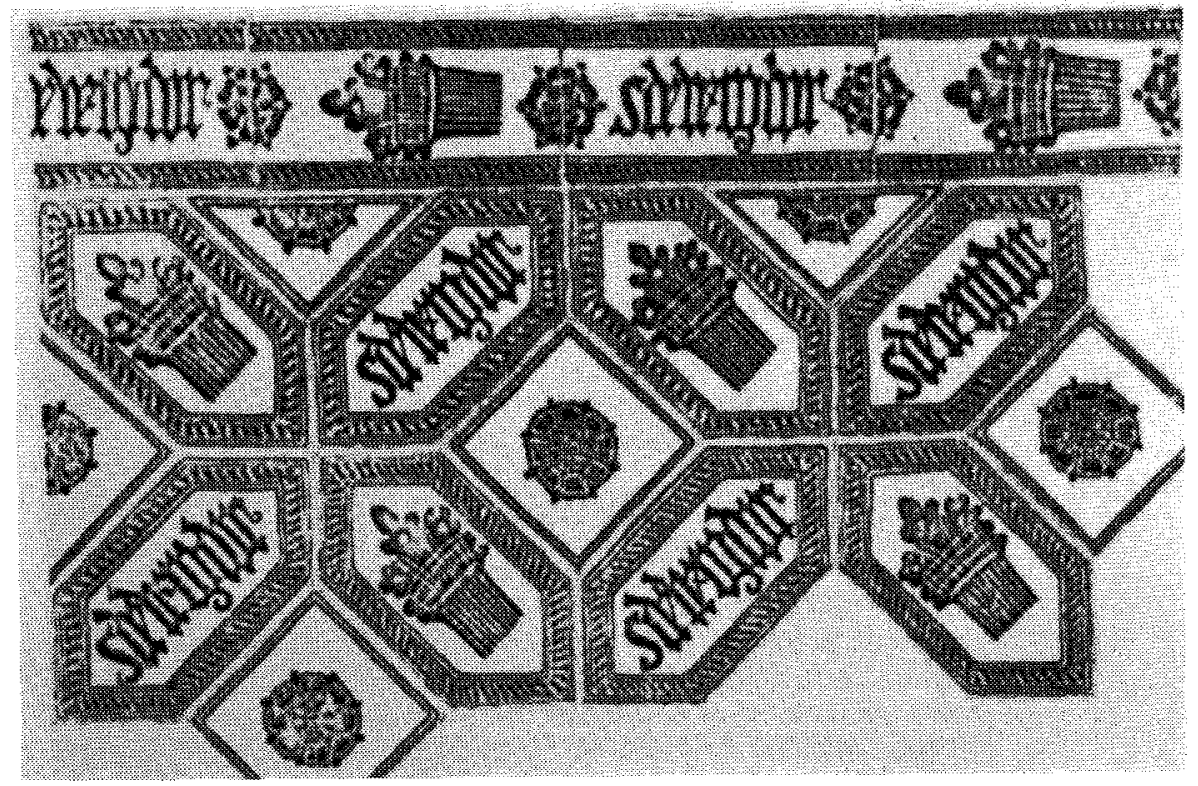

Composición pavimental de azulejos de Manises (s.XV) 


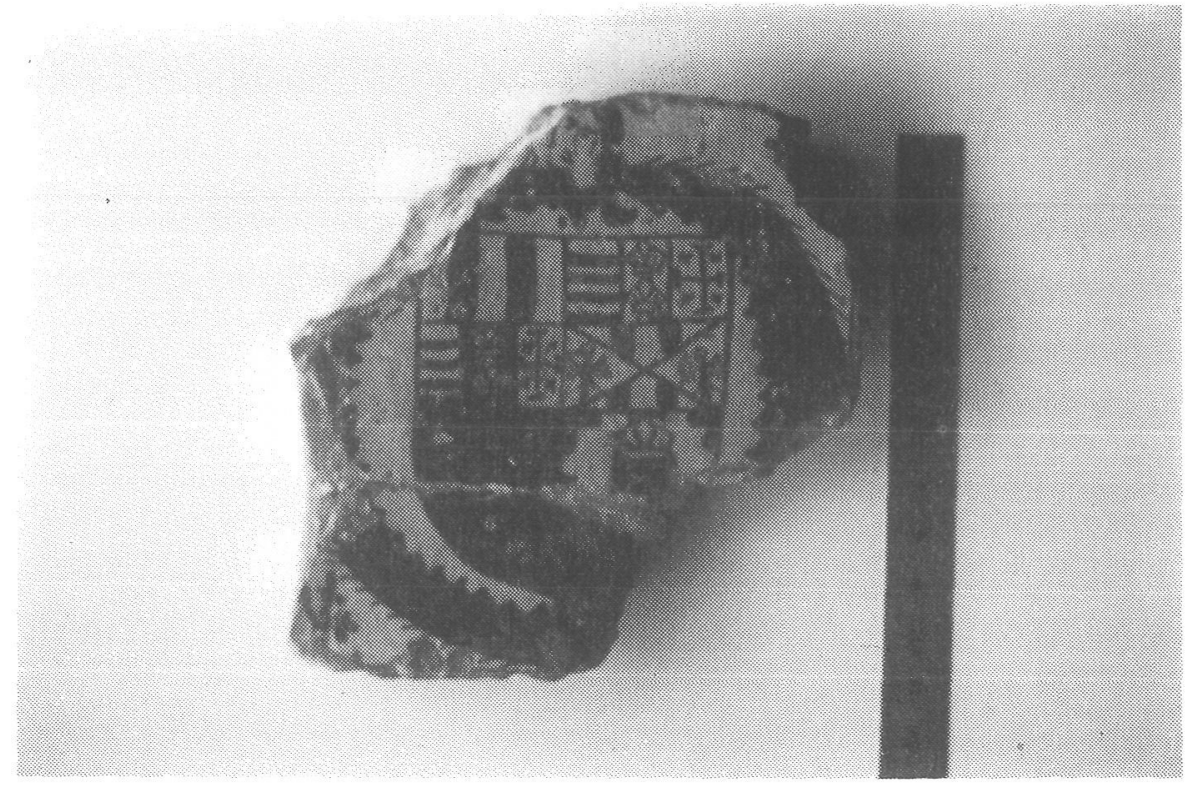

Rajola con el escudo de armas y divisa de Ximen Pérez de Corella del Castillo de Elda (Museo Arqueológico de Elda)

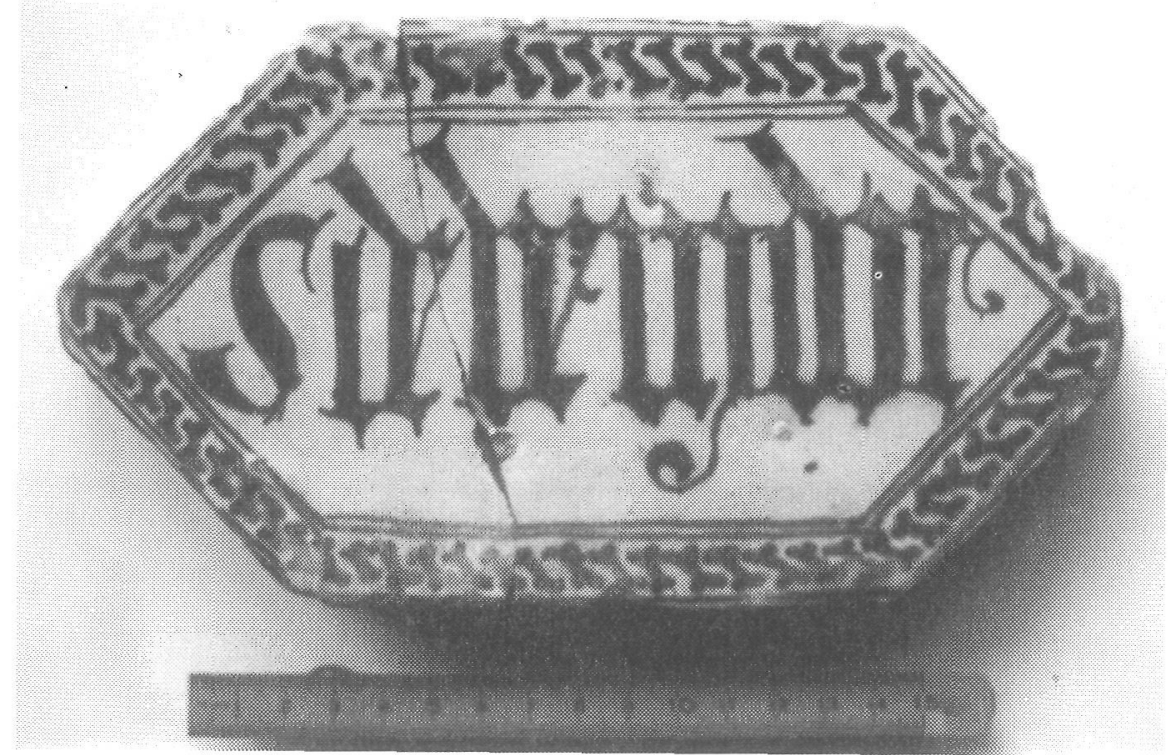

Alfardón con el lema de Ximen Pérez de Corella y su familia, leyenda sdevenidor = venidero, futuro (Museo Arqueológico de Elda) 


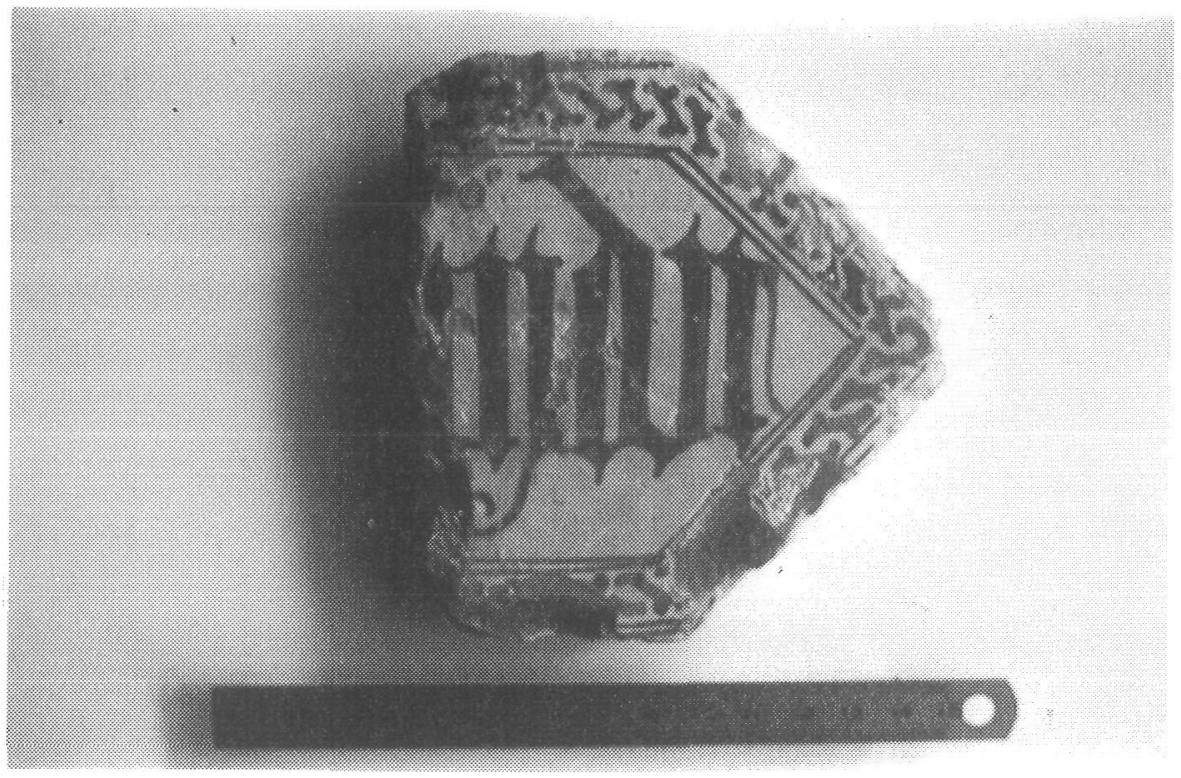

Parte derecha de otro alfardón con el mismo lema de los Corella. (Museo Arqueológico de Elda).

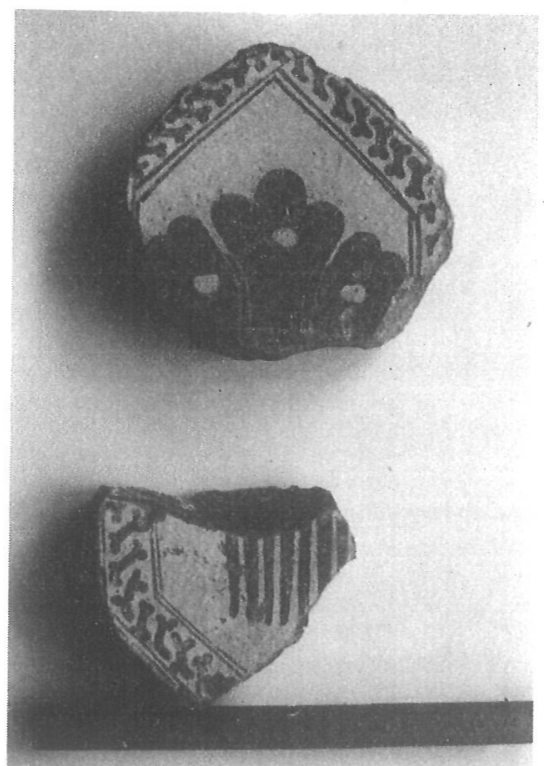

Dos fragmentos de un alfardón con la representación de una peineta medieval valenciana (Museo Arqueológico de Elda). 


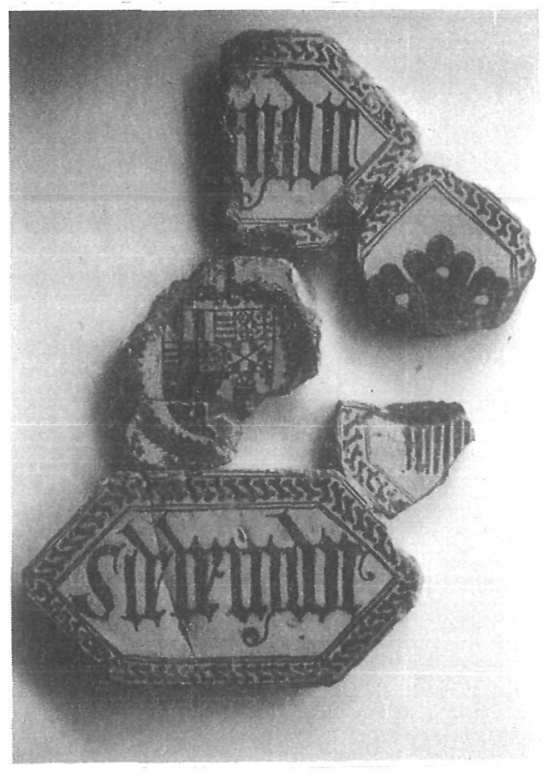

Composición pavimental con los azulejos maniseros del Castillo de Elda

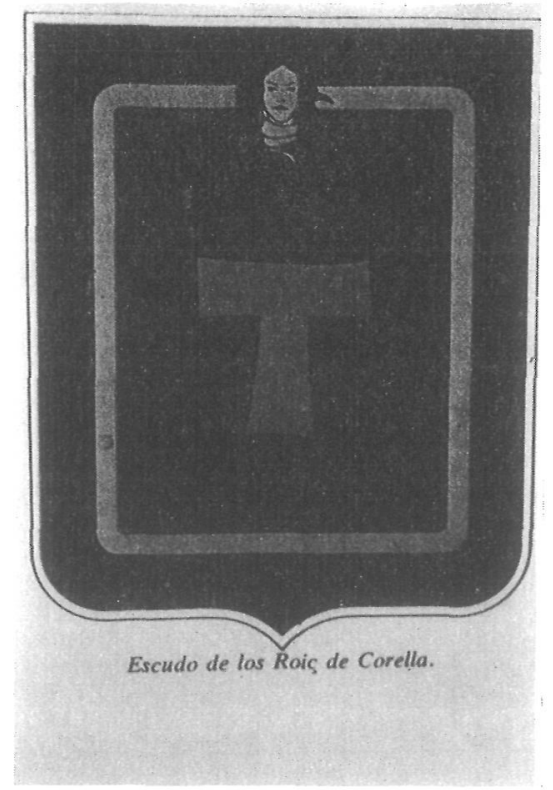

Escudo de armas antiguo de la familia Corella 


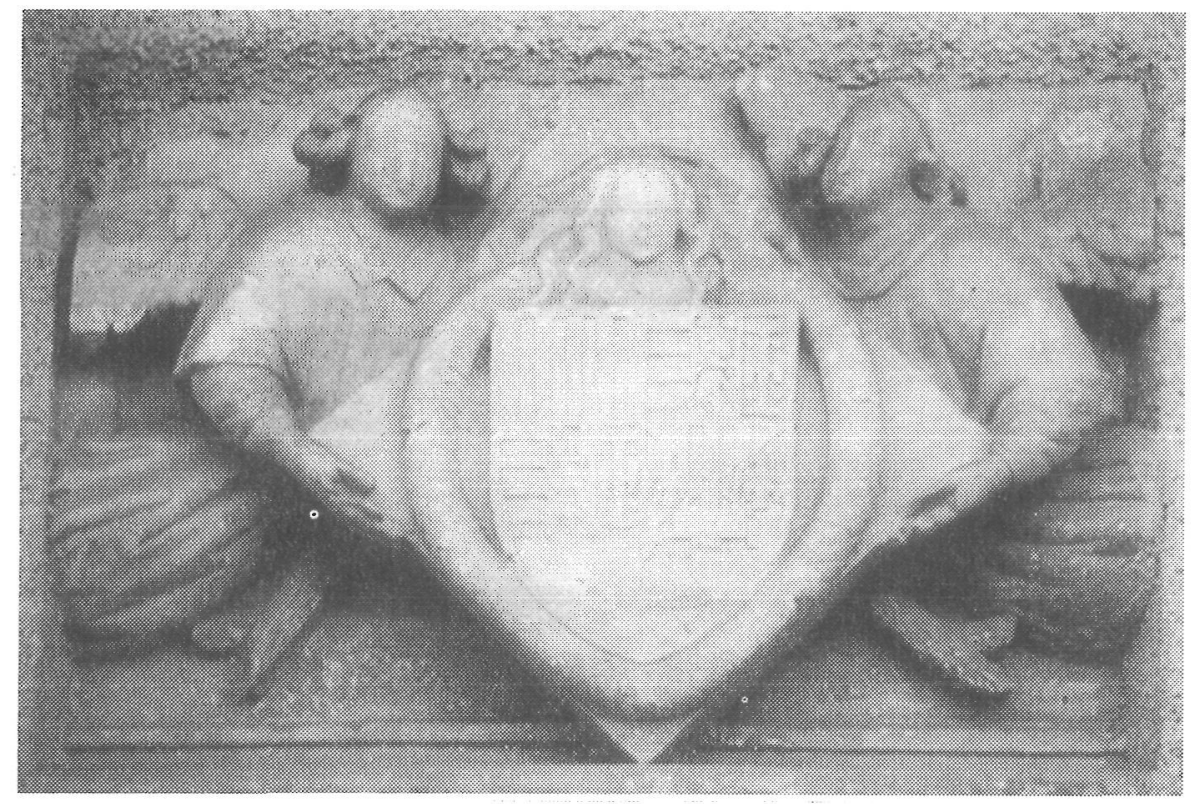

Relieve con el escudo de armas de Ximen Pérez de Corells, carrer Sants Metges en Cocentaina

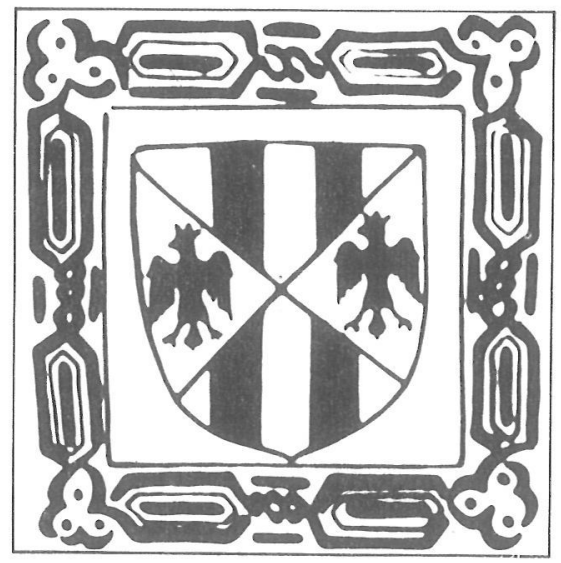

Escudo de armas de Aragón y Sicilia del rey Alfonso V el Magnánimo, sobre azulejo de Manises de mediados del s. XV 


\section{NOTAS}

(1) FUENTES DOCUMENTALES ABREVIADAS.

A. C. A. Archivo de la Corona de Aragón.

A. R. V. Archivo del Reino de Valencia.

A. M. E. Archivo Municipal de Elda.

A. M. Poveda Navarro, "Elda y la familia de los Corella (s.XV)" Alborada, XXIX, Elda-Alicante, 1983, s/p. J. Hinojosa Montalvo, "Las estructuras sociales", en Historia de la Provincia de Alicante. Edad Media, III, Murcia, 1985, p.372.

(2) M. González Martí, Cerámica del Levante español, III, Valencia, 1952, p. 217, fig. 308. A. M. Poveda Navarro, "Elda y la familia ...".

(3) $M^{\mathrm{a}}$ P. Soler Ferrer, "Artes industriales y suntuarias. La cerámica, en Historia del Arte Valenciano, 2. La Edad Media: El Gótico. Valencia, 1988, p. 317.

(4) Martín de Viciana, Crónica de la Inclita y Coronada ciudad de Valencia. Ed. crítica y facsímil de S. García Martínez, Valencia, 1972, parte $2^{a}$, p.140.

(5) Gaspar Escolano, Décadas de Historia de la insigne y coronada ciudad y reino de Valencia. Aumentada con gran caudal de notas, ampliaciones aclaratorias y continuada hasta nuestros dias por J. B. Perales, Valencia, 1878 - 1880, Cap.XLV, p.589.

(6) Varios Autores, El Comtat a l'època medieval (segles XIII-XV), Cocentaina, 1992, p.254.

(7) J. Hinojosa Montalvo, "Las estructuras...", p. 377.

(8) Martín de Viciana, Crónica..., 2ª , p.140.

(9) A. R. V., Manaments y Empares, VI, 1616, fol. 418.

(10) M. González Martí, Cerámica..., p. 217.

(11) Ver nota 9.

(12) B. Martínez Caviró, Cerámica Hispanomusulmana, Madrid, 1991, pp. 205-207.

(13) J. Zurita, Anales de la Corona de Aragón, Zaragoza, 1562-1580, lib. XIII, Cap. XXII.

(14) A.C.A., Reg. 2.920, fol. 102.

(15) A. Almunia, Manual Oriolense (1303-1620), Tesis de Licenciatura inédita de E. Saéz Sánchez, Murcia, 1973, fols. 124-125.

(16) L. Fullana Mira, Historia de la Villa y Condado de Cocentaina, Alcoy, 1975, p. 279.

(17) J. Zurita, Anales..., lib. XIII, Cap. V. 
(18) G. Escolano, Décadas de Historia de la insigne y ..., lib. IX, Cap. XIV.

(19) F. Diago, Apuntamientos recogidos por el P. M. Fr. (...) O. P., para continuar los Anales del Reyno de Valencia desde el Rey Pedro III hasta Felipe II, Valencia, 1936-1947, p.123.

(20) A. R. V., lib. Officialium, 419 , fol. 46 , vto.

(21) A. R. V., Lib. Divers., 257, fol. 146.

(22) L. Fullana Mira, Historia de la Villa..., pp. 290-300.

(23) M. T. Ferrer Mallol, "Eiximèn Peres Roís de Corella y de Santacoloma", en Gran Enciclopedia Catalana, vol. 12, Barcelona, 1978, p. 698.

(24) J. Mateu Ibars, Los Virreyes de Valencia. Fuentes para su estudio. Valencia, 1963, pp.88-90.

(25) A.R.V., Lib. Officialium, 420 , fol.9

(26) L. Fullana Mira, Historia de la Villa...,p. 325

(27) A. R. V., Divers., 291, fol. 140.

(28) A. R. V., Lib. I, Gratiarum Joannis II, 396, fol. 119.

(29) A. R. V., Lib. Divers., 310, fol. 154.

(30) A. C. A., Reg. 2.920, fol. 102. A. C. A., Reg. 2.749 , fols. 227 a 228 vto. A.R.V., Llibre de jurisdiccions de certs baróns. A. Navarro Pastor, Historia de Elda, I, Alicante, 1981, p. 133.

(31) A. M. E., Documento actualmente desaparecido pero que es conocido a través del archivero del ayuntamiento de Elda, del siglo XIX, L. Amat y Sempere, Elda,II, Elda, 1875 (Valencia, 1983), Cap. VII, p. 307.

(32) C. Navarro Poveda, "1503:un conflicto territorial entre Petrel y Castalla", Rev. Moros y Cristianos, Petrer, 1982, s/n.

(33) A. R. V., Real, 44, fol. 2 r-v. J. Hinojosa Montalvo, Textos para la Historia de Alicante. Historia Medieval, Alicante, 1990, pp.341-343.

(34) A. R. V., Lib. Divers., 257, fol. 146.

(35) J. Hinojosa Montalvo, Textos para la Historia..., pp.343 y 345.

(36) A. Navarro Pastor, Historia de Elda, p. 137.

(37) A. R. V. Lib. Divers., 291, fol. 140.

(38) A. Navarro Pastor, Historia de Elda, p. 135.

(39) L. Fullana Mira, Historia de la Villa..., pp. 334-335.

(40) J. M. Salrach, Historia dels Paissos Catalans, I, Barcelona, 1981, p. 605.

(41) A.R.V., Lib. I Gratiarum Joannis II, 396, fol. 119

(42) J. Bautista Vilar, Los siglos XIV y XV en Orihuela, Murcia, 1977, pp. 50-51.

(43) L. Fullana Mira, Historia de la Villa..., p. 285.

(44) A. R. V., Lib. Gratiarum Valentie, 395, fol. 22. L. Fullana Mira, Historia de la Villa..., p. 313. A. Navarro Pastor, Historia de Elda, p. 136.

(45) A. R. V. Lib. I Gratiarum Joannis II, 396, fol. 119.

(46) A. R. V. Lib. Divers., 310, fol. 154. 
(47) A. R. V. Lib. Gratiarum Valentie, 395, fol. 22.

(48) L. Amat y Sempere, Elda, I, Cap. IV, p.21.

(49) L. Amat y Sempere, Elda, II, Cap. Xl, p. 101. G. Vidal Tur, Un obispado español: el de Orihuela-Alicante, I, Alicante, 1961, pp. 57-58. A. Navarro Pastor, Historia de Elda, p. 138. J. Martínez Valls, "Los moriscos de la diócesis de Orihuela a finales del s. XVI", Anales de la Universidad de Alicante. Facultad de Derecho, 1, 1982, pp. 257-258.

(50) L. Amat y Sempere, Elda, II, Cap. X, p. 369. M. Ruzafa García, "El mercado y la feria de Elda en el siglo XV, Alborada, XXX, Elda, 1984, pp. 33-40.

(51) J. M. Soler García, La Relación de Villena de 1575, Alicante, 1969, p. 447.

(52) L. Amat y Sempere, Elda, II, Cap. V, pp. 50-52. A. Navarro Pastor, Historia de Elda, p. 139.

(53) L. Amat y Sempere, Elda, I, Cap. IV, pp. 21-22. A. Navarro Pastor, Historia de Elda, pp. 139-140. 